\title{
La pintora Matilde Aïta de la Peñuela: "una joven artista española, muy meritoria", en el París del Segundo Imperio
}

\author{
The painter Matilde Aïta de la Peñuela: \\ "a young spanish artist, very meritorious", \\ in Paris during the Second Empire
}

Magdalena ILLÁN MARTÍN

Universidad de Sevilla

Recibido: 3-IV-2018

Aceptado: 8-VI-2018

RESUMEN: La pintora Matilde Aïta de la Peñuela fue seleccionada, con 14 años, para representar el arte español en la Exposición Universal de París de 1855. Desde aquel momento participó asiduamente en los Salones y exposiciones francesas, obteniendo notable éxito de crítica y de público, como evidencian los elogios prodigados por críticos como Gautier, Delécluze o el barón Taylor y la demanda de su pintura por parte de reconocidos coleccionistas como Paul Marmottan. Este artículo aporta datos inéditos sobre su biografía y su trayectoria artística localizados en archivos franceses y aborda, especialmente, los desconocidos encargos de su obra por parte del Estado galo.

Palabras clave: Mujeres artistas; Siglo XIX; España; Francia; Cuba; Matilde Aïta.

ABSTRACT: When the painter Matilde Aita de la Peñuela was fourteen, she was selected as artist for Spanish Section of the Paris Universal Exhibition of 1855. Since that moment, she participated in Salones and exhibitions in France and she achieved a great success. Expert critics, as Gautier, Delécluze or Baron Taylor, sang the praises of Aita and his paintings were bought by collectors like Paul Marmottan. This article presents unpublished information about her biography and career, that it is kept in french archives.

Keywords: Women artists; XIX Century; Spain; France; Cube; Matilde Aïta.

Une jeune artiste espagnole, trés honorable, et qui a fait de bonnes études en peinture, à Paris, a présenté et fais recevoir au Salon qui va s'ouvrir un tableau représentant Semíramis ${ }^{1}$. Así se refiere el barón Taylor a los méritos de la

${ }^{1}$ El presente artículo se ha elaborado en el marco del Proyecto I+D "Las artistas en España (1804-1939)", HAR2017-84399-P, Ministerio de Economía, Industria y Competitividad, y del Grupo de Investigación "Laboratorio de Arte", HUM-210, Universidad de Sevilla. pintora Matilde Aïta en la misiva que dirigió a la emperatriz francesa Eugenia ${ }^{2}$, con objeto de instarla a adquirir la obra que la artista

\footnotetext{
${ }^{2}$ Centre d'accueil et de recherche des Archives Nationales de Francia (en adelante CARAN), Legajo F/21/113, Dossier 33, 27-3-1866, fol. 4r: "Una joven artista española, muy meritoria, y que ha realizado buenos estudios de pintura en París, ha presentado y ha sido aceptada en el Salón que se va a inaugurar una pintura que representa a Semíramis".
} 
había presentado en el Salón de 1866 y que, efectivamente, sería comprada por el Estado galo.

Matilde Aïta es conocida, fundamentalmente, por ser la autora del retrato de Simón Bolívar denominado El Libertador (Bolívar diplomático) (1860), convertido en imagen icónica del militar y político venezolano (Fig. $1)^{3}$. No obstante, más allá de dicha obra, la pintora desarrolló una precoz y notable trayectoria artística en el París del Segundo Imperio, una trayectoria que, como señala el historiador cubano Jorge J. Bermúdez, continúa siendo desconocida: "pintora olvidada, a pesar de haber sido la única que fue reconocida por la crítica extranjera" ${ }^{\prime \prime}$. Actualmente, Aïta es valorada como uno de los artistas cubanos más internacionales del siglo XIX y, a pesar de ello, aún son escasas las investigaciones que han arrojado luz sobre su recorrido vital y profesional, siendo sintomática, en este sentido, la exigua producción que se puede atribuir a su mano. De hecho, aunque tenemos constancia, a través de la documentación conservada, de que la artista vivía de su actividad profesional como pintora, sin embargo, la nómina de obras de su autoría que han sido localizadas en colecciones o en catálogos de exposiciones, asciende a un número muy reducido, pudiendo situarse, a tenor de las fuentes investigadas, en torno a la treintena.

\footnotetext{
${ }^{3}$ Sobre la autoría de esta obra -óleo sobre lienzo, 107 x $60 \mathrm{~cm}$.- por parte de Aïta, A. BOULTON, Los retratos de Bolívar, Caracas, 1964, pp. 152-153; E. URIBE WHITE, Iconografía del Libertador, Caracas, 1967, pp. 130-131.

${ }^{4}$ J. J. BERMÚDEZ, De Gutenberg a Landaluze, La Habana, 1990, p. 154. Ciertamente, los estudios sobre la artista realizados hasta el momento son escasos y fragmentarios, formando parte de diccionarios generales sobre artistas cubanos o estudiada exclusivamente a propósito del retrato de Bolívar. Al respecto, es reseñable el manuscrito de once páginas escrito por E. BLANCHET, La señorita doña Matilde Rita de la Peñuela, conservado en la Houghton Library de la Universidad de Harvard y fechado el 21 de octubre de 1860, que traza los inicios formativos de la artista. También es mencionada Aïta como artista de la Escuela Española por E. BÉNÉZIT, Dictionnaire critique et documentaire des peintres, sculpteurs,..., Vol. 1, Paris, 1924, p. 55.
}

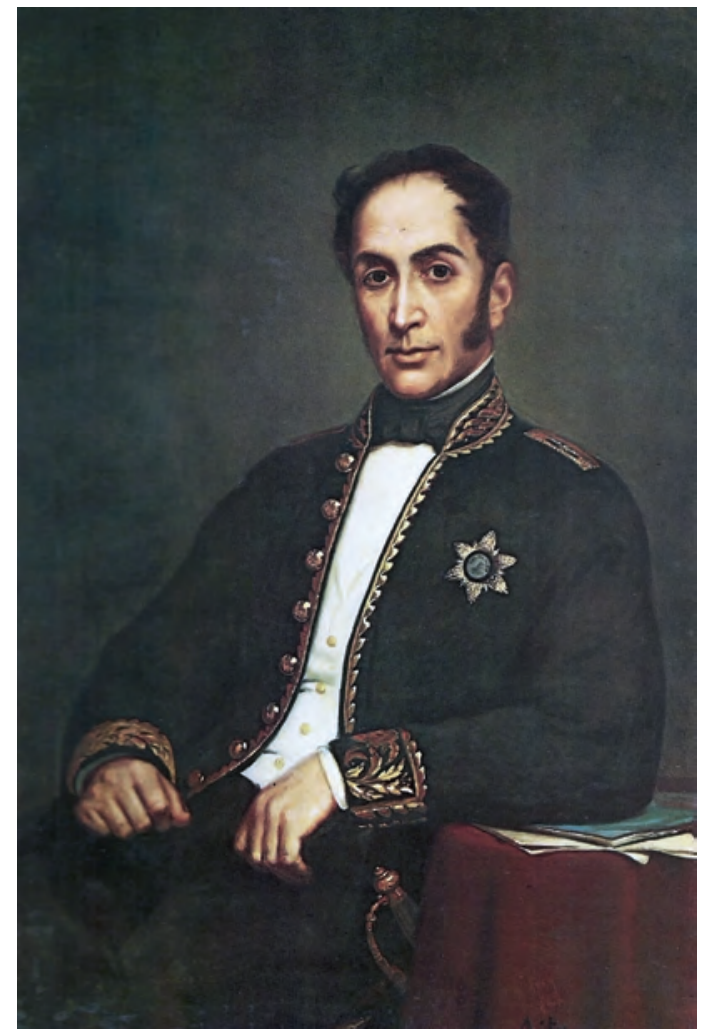

- Fig. 1. Matilde Aïta de la Peñuela. El Libertador (Bolívar diplomático). 1860. Colección del Banco Nacional de Venezuela, Caracas. Foto de la autora.

Este artículo aporta nuevos datos biográficos sobre Aïta procedentes de la documentación conservada en los Archives de Paris y en el Centre d'accueil et de recherche des Archives nationales de Francia. Al respecto, han sido especialmente reveladoras las numerosas cartas que la pintora escribió a las administraciones públicas francesas y que han permitido conocer con mayor precisión las circunstancias vitales que marcaron su existencia desde 1840, año de su nacimiento, a 1870, año en el que se fechan los últimos datos registrados sobre la artista. Igualmente, este artículo proporciona información inédita sobre las pinturas que Aïta realizó por encargo para el Estado francés, así como sobre las adquisiciones llevadas a cabo por los organismos públicos galos, su participación en los Salones y exposiciones francesas y la recepción de su obra por parte de la crítica de arte. Con ello, se persigue actualizar el conocimiento de su trayectoria 
biográfica y profesional, abrir líneas de estudio sobre su obra y poner en valor a una artista que ha sido, en gran medida, olvidada por la historiografía artística, a pesar del notable reconocimiento que alcanzó entre sus contemporáneos.

\section{BIOGRAFÍA DE UNA ARTISTA PRE- $\mathrm{COZ}$}

Nacida en La Habana el 20 de julio de $1840^{5}$, hija de padre español y madre francesa, Matilde Aïta de la Peñuela -que más tarde firmaría sus obras con su primer apellido, Aïta ${ }^{6}$ - comenzó su formación artística con un maestro de dibujo apellidado Zimmerman del que escasas noticias se conocen. El fallecimiento de su padre, acaecido cuando la artista contaba 10 años de edad, determinó que su madre decidiera trasladarse con su hija a su tierra natal, residiendo en la capital gala desde 1850 y donde Aïta obtuvo la nacionalidad francesa ${ }^{7}$. Este traslado sería fundamental para que Matilde pudiera acceder a una formación artística rigurosa y dedicarse profesionalmente a la pintura, superando el habitual estado de "pintora de afición" asignado a las mujeres en el siglo XIX'; en este sentido, señala el escritor e historiador cubano Emilio Blanchet que el motivo por el que la madre decidió su traslado a París fue "que la hija desarrollara su talento. Si no se hubiera marchado, sería una joven de dispo-

\footnotetext{
${ }^{5}$ CARAN, Legajo F/21/113, Dossier 32, 7-4-1863, fol. $1 \mathrm{r}$
}

${ }^{6}$ Hasta ahora se ha considerado que el nombre de la artista era Matilde Rita de la Peñuela; no obstante, en la documentación consultada y firmada por la pintora no figura, en ningún momento, el nombre Rita, sino el apellido Aïta que, en ocasiones, está escrito de tal forma que ha podido ser interpretado como Rita, dando lugar al equívoco ampliamente difundido.

${ }^{7}$ CARAN, Legajo F/21/113, Dossier 32, 1-12-1863, fol. 12r.

${ }^{8} \mathrm{Al}$ respecto, E. de DIEGO, La mujer y la pintura del XIX español, Madrid, 2009; cfr. también el catálogo de la exposición Pintoras en España (1859-1926). De María Luisa de la Riva a Maruja Mallo, Zaragoza, 2014. siciones, una aficionada aplaudida por las visitas de su casa" ${ }^{\prime \prime}$.

En la capital francesa, Aïta residió en el barrio de Saint-Georges del distrito 9, próximo a Montmartre y a la principal zona de comercio de arte, la rue Laffitte, instalándose inicialmente en el número 25 de la rue Fontaine-Saint-Georges y, a partir de 1859, en el número 11 de la rue Pigalle (actual rue Jean-Baptiste Pigalle). Allí continuó su aprendizaje artístico en el estudio de los pintores Ary y Henry Scheffer ${ }^{10}$, con quienes se formó en el género del retrato, $\mathrm{y}$, sobre todo, con la pintora Rosa Bonheur ${ }^{11}$, conocida especialista en la representación de animales, con quien la artista orientó su producción hacia el asunto que mayor reconocimiento le reportaría, la demandada pintura de representaciones de gatos.

Artista precoz, con 14 años Aïta fue seleccionada para representar a España en la Exposición Universal de París de 1855, siendo la única mujer artista entre los cincuenta y cuatro creadores españoles invitados a la muestra. A partir de ese momento y hasta 1869 se tienen noticias de su asidua participación en los Salones parisinos, así como en exposiciones de diferentes localidades francesas, como Rouen (1860), o Amberes (desde 1859). La obra de Aïta alcanzó el reconocimiento de la crítica de arte y un considerable éxito en el mercado artístico, estando presente de forma constante en los escaparates de los marchantes de la Rue Laffitte; asimismo, obtuvo la aprobación de maestros como François-Édouard Picot o Adrien Dauzats, quienes contribuyeron a promover los en-

\footnotetext{
${ }^{9}$ Citado en M. E. LAGUNA ENRIQUE, El Museo Nacional de Bellas Artes de La Habana y la colección de retratos de la pintura española del siglo XIX, Salamanca, 2013, p. 1135.

${ }^{10}$ Exposition Universelle de 1855, Paris, 1855, p. 71; también Salon de 1864, Paris, 1864, p. 4.

${ }^{11}$ Exposition Universelle..., p. 71 ; cfr. también L. DUSSIEUX, Les artistes français a l'étranger, Paris, 1859, p. 381 y X. HEUSCHLING, La noblesse artiste et lettrée. Tableau Historique, Paris, 1863, p. 145.
} 
cargos que la artista ejecutó para el Estado francés.

De espíritu inquieto y emprendedor, Aïta logró dedicarse profesionalmente a la pintura y pudo vivir -tanto ella como su madre- de su trabajo como artista, circunstancia que, probablemente, limitara su producción creativa; en este sentido, se lamenta Blanchet: "vive de su pincel, del género que hasta ahora ha cultivado con acierto sumo; para tentar nuevos caminos, para volar más alto, necesitaría una situación más desahogada"12.

Al margen de la información biográfica extraída de su actividad profesional, son muy escasos los datos conocidos sobre la vida de Aïta, como el viaje que realizó a Roma en 1860, sufragado con sus propios recursos económicos, o el hecho de no haber contraído matrimonio. Debido a esta escasez de información, es interesante examinar la rica -e inédita- relación epistolar que la artista mantuvo con las instituciones culturales francesas, entre ellas, con el ministro de Bellas Artes, el embajador español en Francia o la emperatriz gala. Dichas cartas, conservadas en los archivos consultados, permiten conocer a una joven de 23 años, responsable y segura, que se reivindica como artista y que tiene a su cargo a su madre, con quien reside en el número 11 de la Rue Pigalle y de quien señala que se encuentra enferma de forma permanente ${ }^{13}$. En algunas de sus cartas, Aïta realiza una memoria de su trayectoria profesional, señalando las exposiciones en las que había participado y los nombres de los prestigiosos coleccionistas que habían adquirido sus obras, así como de los artistas y críticos que habían valorado favorablemente su producción pictórica. Dicho material constituye una valiosa documentación para reconstruir su trayectoria vital $\mathrm{y}$, sobre todo, profesional.

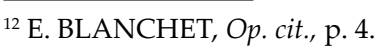

${ }^{13}$ CARAN, Legajo F/21/113, Dossier 32, 1-7-1863, fol. $6 r$.

\section{UNA TRAYECTORIA ARTÍSTICA CON LUCES Y SOMBRAS}

Las primeras noticias sobre la trayectoria artística de Aïta se refieren a su referida participación en la Exposición Universal de París de 1855, en la que expuso junto a pintores como Federico de Madrazo, Eugenio Lucas Velázquez, Carlos Luis de Ribera o Gutiérrez de la Vega; Aïta presentó en dicha muestra dos pinturas: Pequeña espigadora de los Vosgos y Autorretrato ${ }^{14}$. El crítico de arte Théophile Gautier valoró positivamente ambas piezas, la primera por su "vigor y franqueza" y la segunda por su "encanto y veracidad"15; también el pintor y crítico Étienne-Jean Delécluze apreció la primera y mencionó a la artista como ejemplo del carácter cosmopolita de la escuela española ${ }^{16}$. Los dos géneros, costumbrismo y retrato, serían cultivados por la Aïta durante toda su trayectoria, siendo ejemplo de ello la desaparecida pintura Joven habanera llorando su patria (1860) o el ya mencionado retrato de Simón Bolívar, Bolívar diplomático (1859).

A partir de 1855, Aïta participó en diferentes ediciones del Salón parisino y en diversas exposiciones internacionales y regionales, a las que concurrió presentando, en ocasiones, obras ambiciosas, como Semíramis soñando con los muros de Babilonia y, sobre todo, pinturas amables y con temáticas próximas al gusto de las élites sociales del momento. Con estas obras Aïta alcanzaría un notable éxito, como en el Salón de 1859, en el que exhibió la pintura titulada $E l A l$ cibíade moderno ${ }^{17}$, que le proporcionó amplia

${ }^{14}$ El catálogo señala que la artista es discípula de Scheffer y de Rosa Bonheur y que reside en el número 25 de la rue Fontaine-Saint-Georges; las dos obras son los números 616 y 617 de la exposición; Exposition Universelle..., p. 71.

${ }^{15}$ T. GAUTIER, Les Beaux-Arts en Europe. 1855, Paris, 1856, p. 236.

${ }^{16}$ E.-J. DELÉCLUZE, Les Beaux-Arts dans les deux mondes en 1855, Paris, 1856, p. 61.

${ }^{17}$ Salon de 1859, Paris, 1859, p. 4; en dicho catálogo la obra figura con el número 15 y se señala que era discípula de Henry Scheffer, emplazando su residencia en 
fama en el mercado artístico parisino y que fue adquirida por la princesa Sophie Troubetskoï, también duquesa de Morny y dama de la Zarina, quien desempeñó un influyente papel en la corte de Napoleón III, hermanastro de su marido. En la década de 1860, la artista volvió a ser seleccionada para participar en el Salón de 1864 con dos obras - $\mathrm{La}$ hija del Faraón y Autorretrato ${ }^{18}$ - y en el Salón de 1865 participó con una cabeza titulada $\mathrm{La}$ $\mathrm{Fe}^{19}$. En esa misma década, expuso Un estudio en la Sección Española de la Exposición Universal de París de $1867^{20}$, volviendo a concurrir al Salón de 1868 con la pintura Confidencia $^{21}$ y al de 1869 con La lectora ${ }^{22}$. Además de las exposiciones parisinas, Aïta participó en otras muestras galas, como en la Exposición de Rouen de 1860, en la que presentó la pintura El juego del escondite, que fue valorada muy favorablemente por el escritor y crítico de arte Adrien Paul, quien destacó en ella la esmerada captación del movimiento de los animales ${ }^{23}$.

De forma paralela a su participación en las referidas exposiciones, Aïta desarrolló una intensa actividad para la promoción de su obra a través del establecimiento de contactos con relevantes artistas, críticos, políticos, coleccionistas y marchantes. Ello le permitiría exhibir sus pinturas en las galerías comerciales de la Rue Laffitte, así como obtener encargos de la administración pública

la Rue Pigalle, 11.

${ }^{18}$ Salon de 1864, p. 4, en el que figuran como obras de Aita los números 17 -Fille des Pharaon- y 18 -Portrait de l'auteur-.

${ }^{19}$ Salon de 1865, París, 1865, p. 3.

${ }^{20}$ En dicha exposición, Aïta fue, nuevamente, la única mujer artista entre los setenta artistas seleccionados para representar el arte español contemporáneo; Catalogue Général de la Section Espagnole, Exposition Universelle de 1867, Paris, 1867, p. 105.

${ }^{21}$ Salon de 1868, Paris, 1868, p. 3, número 15, con el título Confidence.

${ }^{22}$ Salon de 1869, Paris, 1869, p. 3, número 17, titulado La liseuse.

${ }^{23}$ A. PAUL, "Beaux-Arts. Musée de Rouen-Exposition", Le Siècle, 29-6-1860, p. 3. francesa y de coleccionistas privados. De hecho, la artista refiere en sus escritos que realizó numerosos retratos de mujeres pertenecientes a las élites sociales parisinas, aunque en la actualidad apenas se conocen obras que puedan corroborar sus palabras, muy probablemente porque dichos retratos se conservan en colecciones privadas de difícil acceso. En este sentido, ha de ser incorporada al catálogo de obras de la artista una pintura que representa un Retrato de mujer y que también ha sido denominada Retrato de Madame Christine Boyer o Madame Lucien Bonaparte, aunque realmente se desconoce la identidad de la efigiada; dicha obra se conserva en el Musée National des Châteaux de Malmaison et de Bois-Préu de Francia y fue adquirida por el prestigioso coleccionista Paul Marmottan, quien la donó al Estado galo $^{24}$.

\section{LA PINTORA DEL "SECRETO DE TO- DAS LAS GRACIAS FELINAS"}

A finales de la década de 1850 Aïta se convirtió en una de las artistas más afamadas de París en la temática que mayores reconocimientos le reportaría: las representaciones de gatos. Lejos de tratarse de un tema anecdótico, las pinturas protagonizadas por felinos domésticos constituían en la Francia decimonónica un valorado asunto, que se convirtió, a partir de la influencia tardorromántica, en una refinada moda entre las élites sociales de mediados de la centuria ${ }^{25}$,

\footnotetext{
${ }^{24}$ La pintura, cuyas medidas son $46 \times 38 \mathrm{~cm}$, está firmada por la artista: "M. Aïta". Lamentablemente, debido a su delicado estado de conservación, la obra se encuentra en las áreas de reserva del museo y no ha sido posible obtener una fotografía de la misma.

${ }^{25}$ A ello contribuyó el hecho de que los avances científicos demostraron la escrupulosa higiene de estos animales, lo cual convirtió a los gatos en los animales domésticos por antonomasia en la sociedad decimonónica. La afición de la élite social europea por los gatos se evidencia desde mediados del siglo XIX en las numerosas publicaciones editadas sobre estándares de belleza, la creación de exposiciones felinas -como la celebrada en la Exposición Universal de Londres de 1857- o la creación de asociaciones y clubes.
} 
dedicándose a estos distinguidos animales no sólo pinturas y esculturas, sino también entusiastas páginas de escritores y críticos de arte como Baudelaire, Gautier, Chateaubriand, Hugo o Champfleury ${ }^{26}$. Los felinos representados en estas obras eran, especialmente, los denominados "gatos franceses" o "gatos orientales", es decir, los conocidos en la actualidad como persas o angoras turcos. Se trata de felinos de pelo largo "fino, sedoso y suave", de colores "tenues blancos, cenizas, azul-gris, lila", con ojos azul claro "delicados y tranquilos" 27 , cuya elegancia y sofisticación fueron asociadas al refinamiento de la aristocracia y alta burguesía. En este sentido, numerosas representaciones pictóricas de esos exquisitos felinos introducían en las composiciones elementos característicos de la pintura orientalizante, disponiendo a los animales en suntuosos espacios decorados con alfombras persas, cojines con brocados damascenos, cerámicas árabes o faroles con celosías de arabescos, que recreaban exuberantes entornos envueltos por atmósferas de intenso exotismo oriental ${ }^{28}$.

La formación de Aïta con la pintora Rosa Bonheur, ampliamente valorada por sus obras protagonizadas por animales ${ }^{29}$, le permitió acceder a conocimientos precisos sobre anatomía animal. Ello capacitó a la artista para que sus representaciones de gatos estuvieran construidas a partir de rigurosos estudios anatómicos, lo que llevaría al escritor y crítico de arte francés Gautier a valorar

\footnotetext{
${ }^{26}$ J. CHAMPFLEURY, Les chats, histoire, moeur, observations, anecdotes, Paris, 1869.

${ }^{27}$ Así los describe Charles Henry Ross en su popular libro The book of Cats, publicado en Londres en 1868.

28 Véanse especialmente las obras de Henriette Ronner-Knip, Carl Kahler, William Luker, Jules Leroy, Jane D'Hazon, Delacroix, Louis-Eugène Lambert, Gottfried Mind, Theóphile Steinlen, etc.

${ }^{29}$ Aunque Bonheur no manifestó especial predilección por la representación de animales domésticos - prefiriendo representar animales salvajes, entre ellos felinos como tigres o leones-, sin embargo llegó a ejecutar algunas representaciones de perros y de gatos, como la escultura Gato sentado, el grabado Niña y gato o la pintura El gato salvaje (1850).
}

su riguroso sentido del dibujo y a subrayar al respecto: "bajo esas mantas sedosas reproduce perfectamente la armazón interior del animal" ${ }^{\prime 30}$. Gautier, gran admirador y coleccionista de la obra de Aïta ${ }^{31}$, escribió diferentes críticas sobre la artista, de quien destacó que tenía "un talento muy especial para los animales" y, sobre todo, para la recreación de los gatos, señalando que poseía "el secreto de todas las gracias felinas: sabe como nadie pintar esos ojos amarillos como monedas de oro, verdes como crisoprasas, las diminutas narices partidas como los labios de Ana de Austria, las colas más vaporosas de los marabúes, el pelaje semejante a una borla de tocador, llena de polvos a la mariscala"32. El influyente crítico francés se entusiasma en sus escritos con las pinturas de Aïta y se recrea en la descripción de los felinos representados por la artista, destacando algunas de sus obras, como "una magnífica gata con pelo blanco como el plumón de un cisne, y dispuesta espiritualmente como un genio protector... sobre una partitura de la Cenicienta, que hemos admirado en el escaparate de un marchante de cuadros de la Rue Laffitte" ${ }^{\prime 33}$. También se refiere el escritor a la obra de la artista en su libro Ménagerie intime (1869) cuando, al hablar de la "Dinastía blanca", menciona "un gato traído de La Habana por Mlle. Aïta de la Penuela, joven artista española, cuyos estudios de angoras blancos decoran también los escaparates de los marchantes de grabados, .... un pequeño gato, el más encantador que se pueda imaginar, parecido a esas borlas de cisne con las que se aplica el polvo de arroz" ${ }^{\prime \prime 34}$.

En estas pinturas, y al igual que otros artistas coetáneos, Aïta solía utilizar algunas

${ }^{30}$ T. GAUTIER, Le moniteur Universel, 6-8-1859, p. 2.

${ }^{31}$ Además de las elogiosas críticas de arte que publicó sobre la artista, poseyó una pintura de su autoría, protagonizada por gatos, titulada La disputa $(50 \mathrm{x}$ $61 \mathrm{~cm}$ ); cfr. Catalogue de la Collection de Théophile Gautier. Tableaux, aquarelles...., Paris, 1875, p. 3.

\footnotetext{
${ }^{32}$ T. GAUTIER, Le moniteur..... , p. 2.

${ }^{33}$ ÍDEM, Les Beaux Arts..., p. 236.

${ }^{34}$ ÍDEM, Ménagerie intime, Paris, 1869, p. 17.
} 
de sus representaciones de felinos como metáforas de las actitudes y comportamientos de los seres humanos, tratados con sentido del humor y con notables dosis de ironía ${ }^{35}$. Ejemplos representativos al respecto son $E l$ Alcibíades moderno (1859), El juego del escondite (1860), La paz de Villafranca (ca. 1860), El asalto del pastel (ca. 1860) o Recreación inocente (1870), obra esta última que recibió elogiosas críticas del periodista Francisco de Frías y Jacott, conde de Pozos Dulces ${ }^{36}$. En otras ocasiones la artista desecha cualquier interpretación simbólica de la escena y prefiere mostrar a los delicados y sofisticados gatos angora de forma ingenua y afable, retozando entre suntuosos cojines de seda -Gatos ( $c a$. 1870; Fig. 2)-, jugueteando con flores -Dos gatitos blancos jugando con ramos de lilas (ca. 1870; Fig. 3)- o en compañía de otros anima-

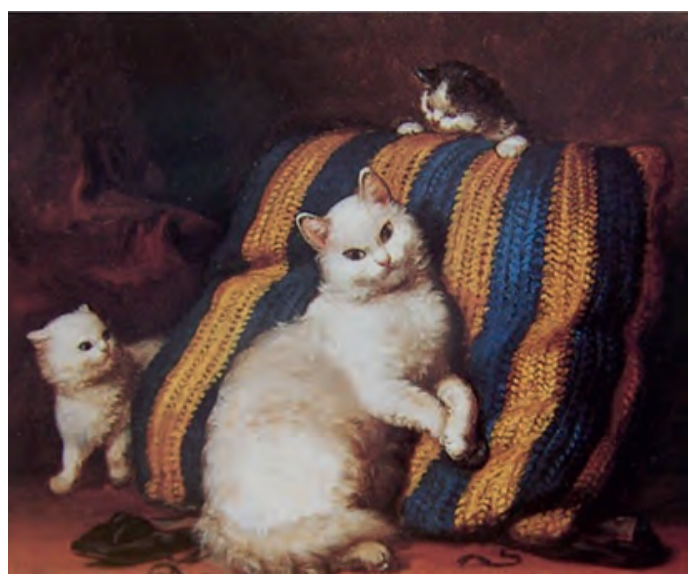

- Fig. 2. Matilde Aïta de la Peñuela. Gatos. Ca. 1870. Foto de la autora.

${ }^{35}$ Las representaciones de animales alegorizando el comportamiento del ser humano adquirieron especial desarrollo en la segunda mitad del siglo XIX. Artistas como Henriette Ronner, Alfred Brunel o Jules Leroy, entre otros, utilizaron felinos; otros artistas, como Paul Schouten o la española Adela Ginés utilizaron escenas de pájaros y gallos como trasunto de las actitudes humanas.

${ }^{36}$ Conde de POZOS DULCES (F. de FRÍAS Y JACOTT), Annuaire de la Gazette de Beaux Artes, 1870. La pintura $-27 \times 35 \mathrm{~cm}-$, que representa a un gato blanco observando dos peces rojos en un cuenco de cristal, fue adquirida por el coleccionista ruso Michel Yakountschikoff; Collection de feu M. Michel Yajountschikoff, Paris, 1870 , p. 15.

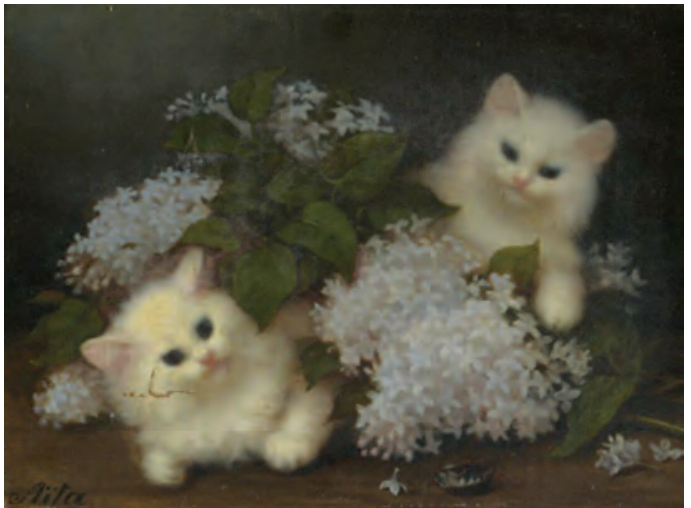

- Fig. 3. Matilde Aïta de la Peñuela. Dos gatitos blancos jugando con un ramo de lilas. Ca. 1870. Foto de la autora.

les -Gato, langosta y paloma y Un gato con un pajarito a sus pies ${ }^{37}$.

\section{ENCARGOS Y ADQUISICIONES DEL ESTADO FRANCÉS}

Entre 1863 y 1870 Matilde Aïta mantuvo una abundante relación epistolar con la administración pública francesa responsable de las adquisiciones de obras artísticas para las colecciones estatales, el Ministère de la Maison de 1'Empereur et des Beaux-Arts. Dicha documentación aporta información relevante sobre las circunstancias vitales de la artista y sobre su personalidad, presentando a una mujer que, a pesar de su juventud, se muestra segura de sus convicciones y orgullosa de su actividad profesional como pintora.

Los motivos por los que Aïta contacta con la administración -dirigiéndose al Ministro Le Comte, al frente del Ministerio de la Casa del Emperador y de Bellas Artes, o a la Emperatriz Eugenia- suelen ser dos: proponer la adquisición de alguna de sus pinturas por parte del Estado o solicitar uno de los habituales encargos para la ejecución

${ }^{37}$ Estas dos últimas obras pertenecieron al coleccionista cubano José Manuel Ximeno y Fuentes, quien también adquirió Un gato y dos gatitos juegan en un cojín, obra que pasó, posteriormente, a formar parte de la colección de Evelio Govantes; D. M. XIMENO Y CRUZ, Aquellos tiempos... Memorias de Lola María, Vol. I, La Habana, 1928, p 349; cfr. también M. E. LAGUNA ENRIQUE, Op. cit., pp. 1132, 1133 y 1135. 
de copias de pinturas de los grandes maestros, destinadas a las instituciones públicas e iglesias galas $^{38}$. En sus cartas, con objeto de poner en valor su talento creativo, la artista incluyó diferentes recomendaciones de personalidades relevantes de la escena cultural francesa, como los pintores FrançoisÉdouard Picot y Adrien Dauzats, la princesa Matilde Bonaparte, el embajador de España en París -Alejandro Mon y Menéndez-, el barón Taylor o el conde Émilien de Niewerkerke, entre otros, quienes elogiaron su capacidad de trabajo y sus méritos.

Las solicitudes remitidas por Aïta -algunas, no sin ciertas dosis de insistencia por parte de la artista- fueron atendidas por los responsables de la administración pública y tres obras de la pintora fueron adquiridas por el Estado francés mediante los referidos sistemas de compra o encargo.

La primera de las pinturas adquiridas por el Estado galo fue comprada por el Ministère de la Maison de l'Empereur et des Beaux-Arts y representa a Semíramis soñando con los muros de Babilonia (1865). Aïta solicitó la adquisición de esta pintura, que había sido remitida al Salón de 1866, a la emperatriz Eugenia, a quien dirigió una misiva fechada en 22 de marzo del referido año ${ }^{39}$; en dicha carta fue incluida, dos días después, una nota del barón Taylor en la que refería los méritos de la artista y recomendaba su compra. Según la documentación consultada, fechada en 29 de marzo de $1866^{40}$, la obra

\footnotetext{
${ }^{38}$ Dicha práctica, la solicitud de encargos estatales por parte de los artistas, no era excepcional en la Francia de la segunda mitad del siglo XIX y numerosos artistas -tanto hombres como mujeres- desarrollaron parte de su producción creativa realizando dichos encargos, pudiendo muchos de ellos subsistir gracias a esta actividad. Durante el Segundo Imperio, los encargos más solicitados eran las copias de los retratos de los emperadores $\mathrm{y}$, en relación a la pintura religiosa, las copias de autores como Murillo, Rafael, Poussin o Tiziano.

${ }^{39}$ CARAN, Legajo F/21/113, Dossier 33, 22-3-1866, fol. $4 \mathrm{r}$; la documentación indica el número de registro de la pintura en el Salón -nº 1963-, aunque en el catálogo de la muestra no se menciona.

${ }^{40}$ Ibídem, 29-3-1866, fol 5r.
}

sería adquirida tras la clausura del Salón y sería incorporada a las colecciones estatales francesas; no obstante, su paradero se ignora en la actualidad y no ha sido localizado ningún grabado o fotografía que permita conocer su fisonomía.

La segunda pintura de Aïta adquirida por el Estado francés es una copia de $E l$ descendimiento de la cruz realizado por Eustache Le Sueur hacia 1651 y conservado en el Museo del Louvre ${ }^{41}$. La artista había solicitado desde 1863, y de forma reiterada a través de diferentes misivas, recibir un encargo de la administración para ejecutar la copia de alguna de las obras conservadas en el museo parisino; dicha solicitud fue satisfecha en 1866, cuando se le encargó la copia de la mencionada pintura de Le Sueur. En el contrato firmado por la artista se especifica el precio establecido por la administración -800 francos-, así como las medidas que había de tener la pintura -similares al original, un tondo de 134 centímetros de diámetro- y un plazo de ejecución de cinco meses. Aïta realizó la copia en menos tiempo del establecido, en cuatro meses, y recibió un informe favorable por parte del inspector, quien señaló que la pintura se había ejecutado con "un dibujo notablemente correcto y una interpretación inteligente del modelo" ${ }^{42}$. $E l$ descendimiento de la cruz (1866) realizado por Aïta se conserva actualmente en la Iglesia de la Asunción de la Virgen de la localidad francesa de Hornoy le Bourg ${ }^{43}$.

Tres años después del último encargo, en 1869, el Estado francés encomendó a Matilde Aïta la ejecución de una tercera pintura. Nuevamente, se trata de la realización de una copia, en esta ocasión, y tal como solicitó la propia artista en una carta dirigida en 1867 al superintendente de Bellas Artes, le comte de Niuwerkerke, sería una copia de

${ }^{41}$ Ibídem, Dossier 32, 3-2-1866, fol. 5r.

${ }^{42}$ Ibídem, 19-6-1866, fol. 8r.

${ }^{43}$ CARAN, Legajo F/21/423, Dossier 9, fol. 3r. Agradezco al Ayuntamiento de Hornoy le Bourg el haber atendido mis solicitudes para conocer la pintura realizada por Aïta. 
un retrato de la emperatriz Eugenia. La obra que la artista recibe el encargo de copiar es el Retrato de la Emperatriz Eugenia realizado por el pintor alemán Franz Xaver Winterhalter en 1853, y que, junto a la pareja del mismo, el Retrato del Emperador, se convirtió en imagen oficial de los emperadores a partir de su exhibición en la Exposición Universal de París de 1855. En el contrato, que tiene un amplio desarrollo administrativo, se especifica, además de los datos habituales, como el precio -600 francos-, las medidas -135 x $101 \mathrm{~cm}-$ y la fecha de entrega -31 de enero de 1870-, que la artista tendría que ejecutar la pintura trabajando de forma exclusiva en los estudios de la Administración de Bellas Artes, situados en el número 182 de la Rue de l'Université $^{44}$. A diferencia del retrato original de Winterhalter, que representa a la emperatriz de cuerpo entero, la obra realizada por Aïta muestra a la efigiada de algo más de medio cuerpo, circunstancia habitual entre las numerosas copias de esta obra que fueron encargadas y cuyo número puede situarse en torno a 400 durante los años de apogeo del Segundo Imperio francés, desde 1855 a 1870. Este Retrato de la Emperatriz Eugenia estaba destinado al hotel de la Sous-Préfecture de la localidad de Indre le Blanc ${ }^{45}$, lugar al que había sido enviado en 1858 un Retrato del Emperador Napoleón III (1857) realizado por Théophile Adolphe Midy ${ }^{46}$, y que con la obra de Aïta vería completada la representación oficial de la pareja de monarcas.

\section{A MODO DE EPÍlOGO}

Las últimas noticias conocidas sobre Matilde Aïta están fechadas en 1870, cuando la artista contaba 29 años de edad. El 15 de enero de dicho año escribió una misiva al Ministère de la Maison de l'Empereur et des Beaux-Arts "suplicando" que se efectuase de $10 \mathrm{r}$

${ }^{44}$ Ibídem, Legajo F/21/113, Dossier 33, 1-10-1869, fol.

${ }^{45}$ Ibídem, Legajo F/21/365, Dossier 5, fol. 2r.

${ }^{46}$ Ibídem, Legajo F/21/98, Dossier 30, fol. 1r y Legajo F/21/365, Dossier 5, fol. 3r. forma urgente el pago del precio estipulado por la realización del mencionado Retrato de la Emperatriz Eugenia. En dicha carta, la artista hace hincapié en la situación "miserable" en la que se encuentra ${ }^{47}$. También en ese mismo año de 1870 el Anuario que cada año publicaba La Gazette des Beaux-Arts y en el que se recogían los datos de los artistas activos en París, menciona a la pintora y su dirección de contacto: "Aita de la Pennuela (Mlle. Mathilde), rue Pigalle, 11; née à La Havane (Antilles espagnoles)" ${ }^{\prime 4}$. A partir de este momento no se conocen más referencias sobre la artista, dejando de concurrir a las exposiciones francesas y de remitir sus habituales solicitudes de compra de obras o de encargos a la administración pública.

Tres décadas más tarde, en 1900 y en el periódico L'Intermédiaire, el historiador $\mathrm{cu}-$ bano Domingo Figarola Caneda se interesaba por obtener información sobre la pintora, a la que se refiere como "Matilde Rita de la Peñuela" y a quien vincula con Rosa Bonheur. En la breve nota de prensa que Figarola escribe lanza una serie de interrogantes acerca del eventual fallecimiento de la artista $\mathrm{y}$, si este aconteció, sobre la fecha del mismo, también se pregunta sobre los premios obtenidos en los Salones o sobre las obras que mostró en las exposiciones francesas ${ }^{49}$. Ignoramos si el investigador obtuvo respuestas a sus preguntas, aunque es probable que no, ya que no publicó ninguna información al respecto. De hecho, a pesar de las investigaciones realizadas, la fecha del fallecimiento de Aïta continúa siendo desconocida, continúa ignorándose gran parte de su trayectoria profesional y continúa siendo necesario localizar su producción y configurar un catálogo que permita valorar de forma coherente su talento; un talento, según Blanchet, de

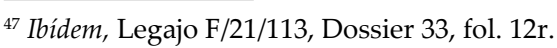

${ }^{48}$ Annuaire publié par La Gazette des Beaux-Arts, Paris 1870, p. 4.

${ }^{49}$ D. FIGAROLA CANEDA, "Matilde Rita de la Peñuela", L'Intermédiaire des chercheurs et curieux: Notes and queries français: questions et réponses, Vol. 41, no ${ }^{\circ} 866$, 01-1900, p. 44
} 
"inspiración ligera y gentil como mariposa, que tiende a transformarse, a sorprendernos, algún día, cual águila sublime ${ }^{\prime 50}$.

\section{BIBLIOGRAFÍA}

DIEGO, E. de, FOUCHER, C., ILLÁN, M. y LOMBA, C., Pintoras en España (18591926). De María Luisa de la Riva a Maruja Mallo. Catálogo de la exposición, Zaragoza, 2014.

BÉNÉZIT, E., Dictionnaire critique et documentaire des peintres, sculpteurs, dessinateurs et graveurs, Vol. 1, Paris, 1924.

BERMÚDEZ, J. J., De Gutenberg a Landaluze, La Habana, 1990.

BLANCHET, E., La señorita doña Matilde Rita de la Peñuela, 1860.

BOULTON, A., Los retratos de Bolívar, Caracas, 1964.

Catalogue Général de la Section Espagnole, Exposition Universelle de 1867, Paris, 1867.

Catalogue de la Collection de Théophile Gautier. Tableaux, aquarelles...., Paris, 1875.

Collection de feu M. Michel Yajountschikoff, Paris, 1870.

CHAMPFLEURY, J., Les chats, histoire, moeur, observations, anecdotes, Paris, 1869.

DELÉCLUZE, E.-J., Les Beaux-Arts dans les deux mondes en 1855, Paris, 1856.

DIEGO, E. de, La mujer y la pintura del XIX español, Madrid, 2009.

DUSSIEUX, L., Les artistes français a l'étranger, Paris, 1859.
Exposition Universelle de 1855, Paris, 1855.

FIGAROLA CANEDA, F., "Matilde Rita de la Peñuela", en L'Intermédiaire des chercheurs et curieux: Notes and queries français: questions et réponses, Vol. 41, no 866, 011900, p. 44.

GAUTIER, T., Les Beaux-Arts en Europe. 1855, Paris, 1856.

GAUTIER, T., Le moniteur Universel, 6-81859 , p. 2.

HEUSCHLING, X., La noblesse artiste et lettrée. Tableau Historique, Paris, 1863.

LAGUNA ENRIQUE, M. E., El Museo Nacional de Bellas Artes de La Habana y la colección de retratos de la pintura española del siglo XIX, Salamanca, 2013.

PAUL, A., "Beaux-Arts. Musée de Rouen-Exposition", Le Siècle, 29-6-1860, p. 3.

POZOS DULCES, Conde de (F. de FRÍAS Y JACOTT), Annuaire de la Gazette de BeauxArts, 1870.

ROSS, C. H., The book of Cats, London, 1868.

Salon de 1859, Paris, 1859.

Salon de 1864, Paris, 1864.

Salon de 1865, Paris, 1865.

Salon de 1868, Paris, 1868.

Salon de 1869, Paris, 1869.

URIBE WHITE, E., Iconografía del Libertador, Caracas, 1967.

XIMENO Y CRUZ, X., Aquellos tiempos... Memorias de Lola María, Vol. I, La Habana, 1928

\footnotetext{
${ }^{50}$ E. BLANCHET, Op. cit., p. 4.
} 